\title{
The Significance of Baroreflex Sensitivity in Hypertensive Subjects with Stroke
}

\author{
D. ČELOVSKÁ ${ }^{1,2}$, J. STAŠKO ${ }^{1}$, J. GONSORČÍKK ${ }^{1}$, A. DIAB ${ }^{1}$ \\ ${ }^{1}$ Fourth Department of Internal Medicine, Pavol Jozef Šafárik University of Košice, Košice, Slovak \\ Republic, ${ }^{2}$ Department of Geriatric Medicine and Gerontology, Pavol Jozef Šafárik University of \\ Košice, Košice, Slovak Republic
}

Received March 7, 2009

Accepted October 7, 2009

On-line November 20, 2009

\begin{abstract}
Summary
The relationship between baroreflex sensitivity expressed in $\mathrm{ms} / \mathrm{mm} \mathrm{Hg}$ (BRS) or in $\mathrm{Hz} / \mathrm{mm} \mathrm{Hg}$ (BRSf) in hypertensives with stroke in comparison with a group of stroke-free patients was evaluated. Twenty-six patients (aged $66 \pm 10$ years, 11 females/ 15 males) with a history of the first ever ischemic stroke (6 months and more after stroke onset), which was neuroradiologically confirmed, were studied. These were compared to 30 hypertensive patients without history of any cardiovascular event, being of similar age and sex. BRS and BRSf were determined by the sequence and spectral methods (fiveminute non-invasive beat-to-beat recording of blood pressure and inter-beat interval, controlled breathing at a frequency of $0.1 \mathrm{~Hz}$ ). A significant negative correlation between spontaneous BRS and blood pressure (BP) represented by the grade of hypertension was present $(r=-0.52, p<0.001)$. Differences between hypertensives with and without stroke were detected in BRS obtained by the spectral method (BRS spect $p=0.0237$, BRSf spect $p=0.0285$ ) or BRS obtained by sequence method (BRS seq $p=0.0532$, BRSf seq $p=0.0273$ ). The greatest decline in BRS values was in hypertensive stroke patients with metabolic syndrome, who had BRS values below $3 \mathrm{~ms} / \mathrm{mm} \mathrm{Hg}$. We found out that BRS and BRSf were more impaired in stroke patients with essential hypertension even 6 months and more after stroke onset than in stroke-free hypertensive patients. This finding was independent of age-dependent decrease of BRS. Examination of baroreflex sensitivity as a marker of autonomic dysfunction along with global cardiovascular risk stratification of individuals seems to be a method for identifying patients at high residual cardiovascular risk.
\end{abstract}

\section{Key words}

Baroreflex sensitivity • Autonomic nervous system • Hypertension - Stroke • Age

\section{Corresponding author}

D. Čelovská, Second Department of Internal Medicine, Faculty of Medicine, Comenius University, Mickiewiczova 13, Bratislava 813 69, Slovak Republic. E-mail: denisa.celovska@gmail.com

\section{Introduction}

Arterial baroreflex is one of the most important physiological mechanisms controlling homeostasis of blood pressure (BP) (Schachter 1997). Impaired baroreflex sensitivity (BRS) is a marker of autonomic dysfunction; it plays a major role in the long-term development of arterial hypertension and related complications (Schachter 1997, Izzo et al. 1999). BP is one of the most powerful determinants of stroke, but not a single one. The function of arterial baroreflex seems to be another important determinant in this process (Liu et al. 2007). Stroke is the third leading cause of death worldwide after heart disease and cancer (Baker 2008). Approximately 15 million people are affected by stroke annually, of whom one third dies and another third is permanently disabled (Baker 2008). Currently, much interest has been focused on the interaction between autonomic dysfunction and global cardiovascular risk. Baroreflex system exhibits a degree of tonic negative feedback by aortic-carotid and cardiopulmonary baroreceptors, so that it can alter sympathetic and parasympathetic nervous system output immediately, providing counter-regulatory increases and decreases in blood pressure to maintain homeostasis (Izzo et al. 1999). The baroreceptors regulate BP by means of vagal 
component that reduces the heart rate or alternatively, by adrenergic component increasing peripheral resistance and heart rate (Schrezenmaier et al. 2007). BRS is quantified in ms of R-R interval duration to each $\mathrm{mm} \mathrm{Hg}$ of arterial pressure. Normal BRS value is approximately $15 \mathrm{~ms} / \mathrm{mm} \mathrm{Hg}$ (La Rovere et al. 2001), but shows large interindividual differences (Jíra et al. 2006). Index BRSf expressed in $\mathrm{Hz} / \mathrm{mm} \mathrm{Hg}$ is less dependent on pulse interval changes than BRS (Al-Kubati et al. 1997). Reduced BRS is associated with a shift in autonomic balance towards sympathetic dominance, which leads to coronary vasoconstriction, platelet aggregability, arrhythmogenesis, impaired ventricular remodelling and higher cardiovascular risk (Mancia et al. 1999, Robinson et al. 2003). Increased activity of sympathetic nervous system together with the renin-angiotensin-aldosterone system result in vascular changes, arterial stiffness, and increased BP eventually causing myocardial hypertrophy (Mancia et al. 1999). These effects contribute to a vicious cycle of hypertension and related complications.

Furthermore, the baroreceptor reflex is considered to be blood pressure buffer system for damping short-term variations of arterial pressure (Schachter 1997). It has always been thought that baroreceptors have minor importance in "chronic" hypertension because of their complete resetting to any new mean arterial pressure level (Persson 2005). The ability of baroreceptors to function at increased BP level is achieved by a process termed as resetting. BP has to remain elevated for 48 hours in order for complete resetting to occur (Krieger 1988). The current role of arterial baroreceptors in hypertension is being reviewed. Baroreflex is the most important nervous regulatory mechanism involved not only in short-term but also in long-term BP control (Persson 2005). Decreased BRS with additional risk factors (obesity, lack of exercise, smoking) in children and adolescents predisposes to the development of an early stage of essential hypertension (Krontorádová et al. 2008).

Mechanisms and effects of blood pressure dysregulation in stroke are not fully elucidated. Central control mechanisms of baroreflex arch that are vital for its integrity may be damaged after stroke (Robinson $e t$ al. 2003). Impaired cardiac BRS may be due to impaired central processing of baroreceptor information following stroke or reduced baroreceptor activity due to increased large artery stiffness (Eveson et al. 2005). Previous experimental studies suggested that BRS is damaged after acute ischemic stroke (within 72 hours of acute stroke onset) and that it predicts the long-term disability and mortality associated with stroke (Robinson et al. 2003). Decreased BRS was found in patients with acute intracerebral hemorrhage and correlated with increased beat-to-beat BP variability (Sykora et al. 2008). The value of baroreflex sensitivity in hypertensive subjects with stroke in chronic phase has not been extensively studied. The aim of the present study was to evaluate the significance of spontaneous BRS and BRSf in hypertensive patients 6 months and more after stroke onset (chronic phase). The relationship between cardiac BRS or BRSf in hypertensives with stroke in comparison with a group of stroke-free patients was evaluated.

\section{Methods}

We studied 56 treated hypertensives ( 32 males/ 24 females). A total of 26 patients ( 15 males/ 11 females, mean \pm S.D.: age $66 \pm 10$ years, range $45-85$ years, body mass index $32.0 \pm 3.5 \mathrm{~kg} / \mathrm{m}^{2}$ ) with a history of the first ever ischemic stroke (6-24 months after stroke onset), which was neuroradiologically confirmed (CT, NMR), were studied. These were compared to 30 hypertensive patients ( 17 males/ 13 females, age $65 \pm 6$ years, range 43 82 years, body mass index $28.5 \pm 3.2 \mathrm{~kg} / \mathrm{m}^{2}$ ) without history of any cardiovascular event. Patients with stroke commonly suffered from type 2 diabetes mellitus (34.6\% vs. $13.3 \%$ ), arrhythmias in the history ( $23.0 \%$ vs. $3.3 \%$ ) in comparison to patients without stroke. Stroke patients had higher body mass index $\left(32.0 \pm 3.5 \mathrm{~kg} / \mathrm{m}^{2}\right.$ vs. $28.5 \pm 3.2$ $\mathrm{kg} / \mathrm{m}^{2}$ ) and surprisingly lower total serum cholesterol level $(4.43 \pm 1.36$ vs. $4.94 \pm 1.20 \mathrm{mmol} / \mathrm{l})$.

The study was performed in the Department of Non-invasive Cardiology at the Faculty of Medicine at UPJS in Košice. All subjects were examined according to standardized protocol. The diagnosis of hypertension was established by Hypertension guidelines from the European Society of Hypertension/European Society of Cardiology 2007, secondary forms of hypertension were excluded. Patients were on standard antihypertensive and hypolipidemic therapy, which included: calcium channel blockers $(n=26)$, beta-blockers $(n=32)$, angiotensinconverting enzyme inhibitors $(n=41)$, diuretics $(n=14)$, central antihypertensive agents $(n=7)$, statins $(n=38)$ and acetylsalicylic acid $(n=28)$. In both groups of subjects there were no significant differences in the standard antihypertensive therapy. Exclusion criteria included the following: atrial fibrilation, recordings of more than five ectopic beats per minute and other cardiac arrhythmias, 
present-day mean systolic BP above $160 \mathrm{~mm} \mathrm{Hg}$ or diastolic BP above $100 \mathrm{~mm} \mathrm{Hg}$, acute myocardial infarction, history and evidence of left ventricular dysfunction, unstable angina, renal function impairment (creatinine more than $200 \mu \mathrm{mol} / \mathrm{l}$ ), age under 18 years, non-cooperative patient, and end-stage diseases. All subjects had a history of arterial hypertension, and were in sinus rhythm. They were hemodynamically stable, independent in their daily living activities, subjects with diabetes mellitus had $\mathrm{HbA}_{1 \mathrm{c}} \leq 6.5 \%$. Patients were from the Department of Geriatric Medicine and Fourth Department of Internal Medicine of the UPJS Faculty Hospital in Košice. All subjects gave their informed written consent, and the local Ethics committee approved of the study.

BP was measured continuously by the noninvasive BP monitor (COLLIN CBM 7000, Japan), with the appropriately sized cuff applied to the wrist of the hemiparetic arm in stroke subjects and non-dominant arm in control subjects. The cuff was maintained at heart level. The non-invasive BP monitor uses vascular unloading technique to measure systolic BP, diastolic BP on a beat-to-beat basis. Control BP was measured in the brachial artery on the other arm by the auscultatory technique. Three surface electrocardiographic chest leads were attached for continuous ECG monitoring.

Patients were asked to avoid alcohol, caffeine and nicotine $24 \mathrm{~h}$ prior to procedure. The examination was performed in a quiet room at a constant temperature with subdued light. After $15 \mathrm{~min}$ of rest, after achievement satisfactory BP and ECG signal and after BP stabilization, first recordings followed. Subjects were laying supine on a coach with their heads propped up.

Special sensor (COLLIN CBM 7000, Japan) was placed around wrist where radial artery is maximally pulsatile for beat-to-beat indirect continuous 5-min blood pressure recordings and inter-beat interval (IBI) measurements. Subjects were asked to maintain the respiratory rate at $17-20$ breaths per minute. They were allowed to adjust the tidal volume according to their own comfort. Breathing was synchronized by a metronome at $0.33 \mathrm{~Hz}$. Three consecutive 5-min recordings of BP and IBI were obtained. In each subject the arithmetic average of three recording was calculated. Signals were low-pass filtered. A non-invasive monitor of BP and IBI (COLLIN CBM 7000, Japan) was used. IBI and BP were recorded simultaneously to a computer with an analogue digital converter. The data were analyzed using specially designed software.
The spontaneous fluctuations in systolic BP and IBI were analysed with the two methods: spectral technique using a protocol of controlled breathing (BRS spect) and sequence technique (BRS seq). We performed cross-spectral analysis to assess the IBI changes associated with systolic BP oscillations. BRS or BRSf was estimated from the modulus of the cross spectrum of $\mathrm{R}-\mathrm{R}$ interval and systolic BP at a frequency of $0.1 \mathrm{~Hz}$. BRSf index was calculated on the basis of the instantaneous value of IBI measured beat-by-beat. The BRS seq was assessed by analyzing the slopes of spontaneously occurring sequences of three or more consecutive beats in which systolic BP and IBI of the following beat increased or decreased in the same direction in a linear fashion.

\section{Statistics}

The data were analyzed using Scope Win 95 software. Statistical data were expressed as mean \pm S.D., category variables in percentage. For each BRS measurement, a single regression analysis was performed. The Pearson coefficients of correlation were calculated for each variable. Comparisons between data obtained in different groups were made by analysis of variance (ANOVA). Antihypertensive medications and statins were not excluded, and therefore they were considered to be another variable. $\mathrm{P}<0.05$ value was considered to be significant. Statistical analysis was performed using Microsoft Office Excel and GNU Octave 2.1.73

\section{Results}

Fifty-six subjects were divided into three groups based on grades of hypertension according to new consensus Hypertension guidelines from the European Society of Hypertension/European Society of Cardiology 2007 (Table 1). The majority of patients belonged to the category of arterial hypertension grade 2 and 3 . Significant negative correlation between spontaneous BRS and BP represented by grade of hypertension was present $(r=-0.52, p<0.001)$. Essential hypertension is associated with decreased BRS/BRSf and the higher the grade of hypertension was present, the lower BRS/BRSf values were found $(p=0.0012 / p=0.0015)$. The most evident decline in BRS/BRSf was in grade 3 of arterial hypertension $(p<0.05 / p<0.05)$, especially in patients with target organ damage as stroke. The value of spontaneous BRS was lower in hypertensive patients with stroke than in stroke-free hypertensive patients: BRS obtained by the 
Table 1. Baroreflex sensitivity values obtained by both sequence and spectral methods based on grade of arterial hypertension.

\begin{tabular}{|c|c|c|c|c|}
\hline $\begin{array}{l}\text { Arterial hypertension } \\
\text { category }\end{array}$ & $\begin{array}{c}\text { SBP } \\
(\mathrm{mm} \mathrm{Hg})\end{array}$ & $\begin{array}{c}\text { DBP } \\
(\mathrm{mm} \mathrm{Hg})\end{array}$ & $\begin{array}{c}\text { BRS seq vs. } \\
\text { BRS spect } \\
\text { (ms/ mm Hg) }\end{array}$ & $\begin{array}{c}\text { BRSf seq vs. } \\
\text { BRSf spect } \\
\text { (Hz/mm Hg) }\end{array}$ \\
\hline $\begin{array}{l}\text { Grade } 1 \\
n=5(8.92 \%)\end{array}$ & $140-159$ & $90-99$ & $\begin{array}{l}8.4 \pm 3.0 \text { vs. } \\
9.5 \pm 4.0\end{array}$ & $\begin{array}{l}0.0082 \pm 0.0040 \text { vs. } \\
0.0090 \pm 0.0035\end{array}$ \\
\hline $\begin{array}{l}\text { Grade } 2 \\
n=22(39.28 \%)\end{array}$ & $160-179$ & $100-109$ & $\begin{array}{l}7.2 \pm 6.9 \text { vs. } \\
8.4 \pm 6.4\end{array}$ & $\begin{array}{l}0.0075 \pm 0.0035 \text { vs. } \\
0.0079 \pm 0.0030\end{array}$ \\
\hline $\begin{array}{l}\text { Grade } 3 \\
n=29(51.78 \%)\end{array}$ & $\geq 180$ & $\geq 110$ & $\begin{array}{l}4.5 \pm 2.5 \text { vs. } \\
6.4 \pm 5.4\end{array}$ & $\begin{array}{l}0.0052 \pm 0.0020 \text { vs. } \\
0.0055 \pm 0.0035\end{array}$ \\
\hline
\end{tabular}

The values are presented as mean \pm S.D., category variables in percentage, BRS - baroreflex sensitivity in $\mathrm{ms} / \mathrm{mm} \mathrm{Hg}, \mathrm{BRSf}-$ baroreflex sensitivity in $\mathrm{Hz} / \mathrm{mm} \mathrm{Hg}$, BRS seq - BRS values obtained by sequence method, BRS spect - BRS values obtained by spectral method, SBP - systolic blood pressure, DBP - diastolic blood pressure.

Table 2. Differences between baroreflex sensitivity parameters in hypertensives and hypertensives with stroke.

\begin{tabular}{lccc}
\hline Parameter & $\begin{array}{c}\text { Hypertensives } \\
\mathbf{n}=\mathbf{3 0}\end{array}$ & $\begin{array}{c}\text { Hypertensives with stroke } \\
\mathbf{n = 2 6}\end{array}$ & P-value \\
\hline SBP $(\mathrm{mm} \mathrm{Hg})$ & $127 \pm 13$ & $139 / 85 \pm 10 / 7$ & 0.0417 \\
DBP $(\mathrm{mm} \mathrm{Hg})$ & $81 \pm 9$ & $139 / 85 \pm 10 / 7$ & $0.0911 \mathrm{NS}$ \\
Inter-beat-interval $(\mathrm{ms})$ & $834 \pm 126$ & $816 \pm 157$ & 0.0451 \\
BRS seq (ms/mm Hg) & $8.4 \pm 6.4$ & $5.9 \pm 3.0$ & $0.0532 \mathrm{NS}$ \\
BRSf seq $(\mathrm{Hz} / \mathrm{mm} \mathrm{Hg})$ & $0.0083 \pm 0.0045$ & $0.0055 \pm 0.0030$ & 0.0273 \\
BRS spect $(\mathrm{ms} / \mathrm{mm} \mathrm{Hg})$ & $6.4 \pm 3.5$ & $4.0 \pm 2.2$ & 0.0237 \\
BRSf spect $(\mathrm{Hz} / \mathrm{mm} \mathrm{Hg})$ & $0.0090 \pm 0.0047$ & $0.0064 \pm 0.0022$ & 0.0285
\end{tabular}

The values are presented as mean \pm S.D., BRS seq - baroreflex sensitivity values obtained by sequence method in $\mathrm{ms} / \mathrm{mm} \mathrm{Hg}$, BRS spect - baroreflex sensitivity values obtained by spectral method in $\mathrm{ms} / \mathrm{mm} \mathrm{Hg}$, BRSf seq - baroreflex sensitivity obtained by sequence method in $\mathrm{Hz} / \mathrm{mm} \mathrm{Hg}$, BRSf spect - baroreflex sensitivity obtained by spectral method in $\mathrm{Hz} / \mathrm{mm} \mathrm{Hg}$, statistical analysis by ANOVA, NS not significant.

spectral method (BRS spect) was $4.0 \pm 2.2$ vs. $6.4 \pm 3.5$ $\mathrm{ms} / \mathrm{mm} \mathrm{Hg}, \mathrm{p}=0.0237$ or BRS obtained by the sequence method (BRS seq) was $5.9 \pm 3.0$ vs. $8.4 \pm 6.4 \mathrm{~ms} / \mathrm{mm} \mathrm{Hg}$, $\mathrm{p}=0.0532$. We also revealed significant BRSf decrease in hypertensives with stroke (BRSf spect $\mathrm{p}=0.0285$, BRSf seq $p=0.0273)$. The differences between baroreflex sensitivity parameters (BRS and BRSf) in hypertensives and hypertensives with stroke are presented in Table 2. The coincidence of arterial hypertension, diabetes mellitus, metabolic syndrome (presence of essential hypertension, insulin resistance, glucose intolerance, abnormal lipoprotein metabolism and central obesity) and stroke is associated with extremely high cardiovascular risk. All 5 patients with these criteria had BRS values below $3 \mathrm{~ms} / \mathrm{mm} \mathrm{Hg}$, higher grade of disability and two of them died during one year. A clinically noticeable difference in gender was not shown in BRS values. The mean BRS seq was $5.5 \pm 3.4 \mathrm{~ms} / \mathrm{mm} \mathrm{Hg}$ in women vs. $5.8 \pm 5.7 \mathrm{~ms} / \mathrm{mm} \mathrm{Hg}$ in men, the mean BRS spect was $6.0 \pm 3.9 \mathrm{~ms} / \mathrm{mm} \mathrm{Hg}$ in women vs. $6.1 \pm 3.8 \mathrm{~ms} / \mathrm{mm} \mathrm{Hg}$ in men.

An inverse relationship between age and BRS has been demonstrated $(r=-0.34, p<0.05)$. BRS determined by the spectral and sequence method was correlated with biological parameters. There was only a slight positive correlation between BRS and serum cholesterol $(\mathrm{r}=0.51, \mathrm{p}<0.05)$.

\section{Discussion}

It was previously shown that BRS was impaired within 72 hours of acute stroke onset (Robinson et al. 2003, Sykora et al. 2008). There is also evidence of abnormal BRS in animal models after stroke and other 
cerebrovascular diseases (Robinson et al. 2003, Liu et al. 2007). Liu et al. (2007) demonstrated that BRS is a new predictor for stroke incidence in hypertensive rats and that pharmacological restoration of arterial baroreflex function by a small dose of ketanserin can delay the occurrence of stroke in the rat. In our study we have demonstrated that the values of BRS and BRSf were significantly lower in hypertensive subjects even 6 months and more after ischemic stroke onset (chronic phase) in comparison to stroke-free hypertensive patients. BRS values reflect baroreceptor sensitivity and balance of the autonomic nervous system in the body, but BRSf index corresponds only to the baroreceptor activity. Using the two indices BRS and IBI-independent BRSf we could evaluate complex BRS and better reflect the development of the BRS (Závodná et al. 2006), especially in patients with target organ damage. Several studies have confirmed that essential hypertension is connected with decreased BRS (Head 1994, Ormezzano et al. 2008). In support of these studies we have confirmed noticeable negative correlation between BRS and BP. Essential hypertension was associated with decreased BRS, and grade of hypertension was inversely correlated with BRS values. The most evident decline in BRS values was found in patients with grade 3 arterial hypertension, especially in those with target organ damage such as stroke. Patients with stroke suffered more from type 2 diabetes mellitus and arrhythmias in the history (atrial fibrillation), had higher body mass index (BMI) and lower total serum cholesterol level in comparison to patients without stroke. Hypertensive stroke patients with metabolic syndrome had BRS values below $3 \mathrm{~ms} / \mathrm{mm} \mathrm{Hg}$. The finding that impaired BRS is not a benign phenomenon was confirmed by Robinson study and multicenter ATRAMI (Autonomic Tone and Reflexes After Myocardial Infarction) study in patients after myocardial infarction. Stroke patients with BRS $\leq 5 \mathrm{~ms} / \mathrm{mm} \mathrm{Hg}$ in the study of Robinson et al. (2003) had a poorer prognosis ( $28 \%$ vs. $8 \%$ mortality rate during follow up period), there were no significant differences in age, stroke severity, stroke type, or casual BP. BRS is an independent risk factor for morbidity and major adverse cardiovascular events in hypertensive patients (Ormezzano et al. 2008). Except for classic risk factors such as elevated blood pressure, abnormal serum lipids or glucose, BRS seems to be an integral predictor for future cardiovascular events in patients with arterial hypertension (Lantelme et al. 2002). Furthermore, it is convenient in clinical practice for being non-invasively measured.

Cerebral infarction can significantly affect cardiovascular regulation that is associated with adverse prognosis. Cardiac complications of stroke patients are common, including ventricular arrhythmias, sudden death and symptoms related to ischemic heart disease. Impaired cardiac BRS after acute stroke may also be associated with central autonomic cardiovascular dysregulation (Robinson et al. 2003, Sykora et al. 2008). Reduced BRS and heart rate variability are independent risk factors for sudden cardiac death (La Rovere et al. 2000). According to ATRAMI and Robinson studies, impaired BRS seems to provide a long-term prognostic value for cardiovascular morbidity and mortality (La Rovere et al. 2000, Robinson et al. 2003).

The influence of population characteristics on the values of BRS was examined. An inverse relationship between BRS and age was demonstrated. A combination of high BP and old age was associated with a significant reduction in BRS. Hypertension and ageing may have a synergistic effect on cardiac parasympathetic function, which ultimately cause a prolongation in baroreflex response (Peckerman et al. 2001). A defect in central mediation of arterial baroreflex, especially in stroke patients, may be the major cause of impaired baroreflex with aging rather than decreased vascular distensibility or a defect in the generation of baroreceptor activity (Chapleau et al. 2005). A total of 26 hypertensive subjects with stroke were compared to 30 hypertensive patients, being of similar age, to eliminate age-dependent decrease of BRS. Age-dependent decrease of BRS corresponds to the age-related structural changes of the carotid wall (Lábrová et al. 2005). Measurement of intima-media thickness of the carotid wall along with BRS measurement seems to be additive method for identification of cardiovascular risk in hypertensives and subclinical atherosclerosis in subjects with high normal BP. Reduced BRS values could identify residual risk of cardiovascular disease in patients with statin therapy. There was no significant difference in BRS values in both genders.

Antihypertensive and statin therapy, which was not excluded, could have influenced BRS values. Longterm BP control with modern antihypertensive drugs such as angiotensin converting enzyme inhibitors (ACEI), angiotensin II receptor blockers, calcium channel and beta-blockers improves baroreflex functions (Chen et al. 1999, Gonsorčík et al. 2002, Munakata et al. 2003). Despite the fact that potential increases in BRS values may have resulted from these medications in hypertensive and stroke patients, they had BRS values still impaired in 
comparison with healthy subjects. It is evident that the influence of medication on BRS values and interpretation of results needs more investigation in the future. The present study should have a prospective focus in order to establish BRS as a novel risk stratifier in hypertensive patients.

We conclude that autonomous nervous dysfunction and the inappropriately active sympathetic nervous system in patients with arterial hypertension is an important etiopathogenetic factor that contributes also to progression of disease, and the resultant cardiovascular risk. In this study, BRS and BRSf values were more impaired in ischemic stroke patients (chronic phase) with essential hypertension than in stroke-free hypertensive patients. Hypertensive stroke patients with metabolic syndrome features had BRS values below $3 \mathrm{~ms} / \mathrm{mm} \mathrm{Hg}$. Examination of baroreflex sensitivity as a marker of autonomic dysfunction along with global cardiovascular risk stratification of individuals seems to be a method for identifying patients at high cardiovascular risk. Using the two indices BRS and IBI-independent BRSf we could evaluate complex BRS and better reflect the development of the BRS in patients with target organ damage.

\section{Conflict of Interest}

There is no conflict of interest.

\section{Acknowledgements}

There is no form of financial support or grant associated with this study.

\section{References}

AL KUBATI MAA, FIŠER B, SIEGELOVÁ J: Baroreflex sensitivity during psychological stress. Physiol Res 46: 3137, 1997.

BAKER M: Posibilities of reduction stroke incidence. Med Practice 7-8: 31-33, 2008.

CHAPLEAU MW, CUNNINGHAM JT, SULLIVAN MJ, WACHTEL RE, ABBOUD FM: Structural versus functional modulation of the arterial baroreflex. Hypertension 26: 341-347, 1995.

CHEN X, HASSAN MO, JONES JV, SLEIGHT P, FLORAS JS: Baroreflex sensitivity and the blood pressure response to beta-blockade. J Hum Hypertens 13: 185-190, 1999.

EVESON DJ, ROBINSON TG, SHAH NS, PANERAI RB, PAUL SK, POTTER JF: Abnormalities in cardiac baroreceptor sensitivity in acute ischaemic stroke patients are related to aortic stiffness. Clin Sci 108: 441-447, 2005.

GONSORČÍK J, FARKAŠ A, RAJNIČ A: Candesartan improves baroreflex sensitivity in hypertensive patients with mild chronic renal failure. In: Cardionephrology 7. M TIMIO, V WIZERMAN, S VENANZI (eds), Editoriale Bios, Assisi, 2002, pp 247-248.

HEAD GA: Cardiac baroreflexes and hypertension. Clin Exp Pharmacol Physiol 21: 791-802, 1994.

IZZO JL, TAYLOR AA: The sympathetic nervous system and baroreflexes in hypertension and hypotension. Curr Hypertens Rep 1: 254-263, 1999.

JÍRA M, ZÁVODNÁ E, HONZÍKOVÁ N, NOVÁKOVÁ Z, FIŠER B: Baroreflex sensitivity as an individual characteristic feature. Physiol Res 53: 349-351, 2006.

KRIEGER EM: Mechanisms of complete baroreceptor resetting in hypertension. Drugs 35: 98-103, 1988.

KRONTORÁDOVÁ K, HONZÍKOVÁ N, FIŠER B, NOVÁKOVÁ Z, ZÁVODNÁ E, HRSTKOVÁ H, HONZÍK P: Overweight and decreased baroreflex sensitivity as independent risk factors for hypertension in children, adolescents and young adults. Physiol Res 57: 385-391, 2008.

LÁBROVÁ R, HONZÍKOVÁ N, MADĚROVÁ E, VYSOČANOVÁ P, NOVÁKOVÁ Z, ZÁVODNÁ E, FIŠER B, SEMRÁD B: Age-dependent relationship between the carotid intima-media thickness, baroreflex sensitivity, and the inter-beat interval in normotensive and hypertensive subjects. Physiol Res 54: 593-600, 2005.

LANTELME P, KHETTAB F, CUSTAUD MA, RIAL MO, JOANNY C, GHARIB C, MILON H: Spontaneous baroreflex sensitivity: toward an ideal index of cardiovascular risk in hypertension? J Hypertens 20: 935-944, 2002.

LA ROVERE MT: Baroreflex sensitivity as a new marker for risk stratification. Z Kardiol 89: 44-50, 2000.

LA ROVERE MT, GNEMNI N, VACCARINI C: Baroreflex sensitivity. Ital Heart J 2: 472-477, 2001. 
LIU AJ, MA XJ, SHEN FM, LIU JG, CHEN H, SU DF: Arterial baroreflex a novel target for preventing stroke in rat hypertension. Stroke 38: 1916-1923, 2007.

MANCIA G, GRASSI G, GIANNATTASIO C, SERAVALLE G: Sympathetic activation in pathogenesis of hypertension and progression of organ damage. Hypertension 34: 724-728, 1999.

MUNAKATA M, AIHARA A, NUNOKAWA T, ITO N, IMAI Y, ITO S, YOSHINAGA K: The influence of one-year treatment by angiotensin converting enzyme inhibitor on baroreflex sensitivity and flow-mediated vasodilation of the brachial artery in essential hypertension-comparison with calcium chanel blockers. Clin Exp Hypertens 25: 169-181, 2003.

ORMEZZANO O, CRACOWSKI JL, QUESADA JL, PIERRE H, MALLION JM, BAQUET JP: Evaluation of the prognostic values of baroreflex sensitivity in hypertensive patients: the EVABAR study. J Hypertens 26: 1373$1378,2008$.

PECKERMAN A, HURWITZ BE, NAGEL JH, LEITTEN C, AGATSON AS, SCHNEIDERMAN N: Effects of gender and age on the cardiac baroreceptor reflex in hypertension. Clin Exp Hypertens 23: 645-656, 2001.

PERSSON PB: Baroreflexes in hypertension: a mystery revisited. Hypertension 46: 1095-1096, 2005.

ROBINSON TG, DAWSON SL, EAMES PJ, PANERAI RB, POTTER JF: Cardiac baroreceptor sensitivity predicts long-term outcome after acute ischemic stroke. Stroke 34: 705-712, 2003.

SCHACHTER M: The Sympathetic Nervous System and Hypertension. Martin Dunitz Ltd, London, 1997, pp 1-56.

SCHREZENMAIER C, SINGER W, MAUENTER S, SLETTEN D, TANABE J, LEVO P: Adrenergic and vagal baroreflex sensitivity in autonomic failure. Arch Neurol 64: 381-386, 2007.

SYKORA M, DIEDLER J, RUPP A, TURCANI P, ROCCO A, STEINER T: Impaired baroreflex sensitivity predicts outcome of acute intracerebral hemorrhage. Crit Care Med 36: 3074-3079, 2008.

ZÁVODNÁ E, HONZÍKOVÁ N, HRSTKOVÁ H, NOVÁKOVÁ Z, MOUDR J, JÍRA M, FIŠER B: Can we detect the development of baroreceptor sensitivity in humans between 11-20 years of age? Can J Physiol Pharmacol 84: 1275-1283, 2006. 